\title{
Composite Model of Full GP Structure of Ebola Virus Envelope Glycoprotein
}

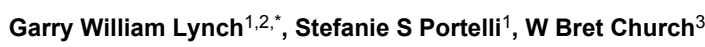 \\ ${ }^{1}$ The University of Sydney, Faculty of Medicine, Camperdown, NSW, 2006, Australia \\ ${ }^{2}$ The University of Sydney, Faculty of Veterinary Science, Camperdown, NSW, 2006, Australia \\ ${ }^{3}$ The University of Sydney, Faculty of Pharmacy, Camperdown, NSW, 2006, Australia
}

*Corresponding author: Garry William Lynch, Senior Lecturer/Senior Research Fellow, University of Sydney, Faculties of Medicine \& Veterinary Science, Rm 551 Gunn Bldg (B19), Sydney, NSW 2006, Australia, E-mail: garry.lynch@sydney.edu.au

Received date: March 27, 2015; Accepted date: March 29, 2015; Published date: April 06, 2015

Copyright: ( 2015 Lynch GW. This is an open-access article distributed under the terms of the Creative Commons Attribution License, which permits unrestricted use, distribution, and reproduction in any medium, provided the original author and source are credited.

\section{Description}

Depicted is a composite model of the Ebola surface glycoprotein (GP) in its trimeric configuration (monomers comprise GP1GP2 subunits) and represents a single GP spike projecting from the surface of the Ebola Virus. This figure combines the published X-ray crystallographic (core) [1] and cryoelectron tomography (global) [2] structures, together now with in silico modeled sections of the mucinlike domain and separately the GP stalk [3]. The latter are missing from earlier published crystal structure determinations. The core Ebola Virus glycoprotein GP 3CSY structure (of homo-trimers of truncated GP1-GP2 monomers) was determined by $\mathrm{x}$-ray crystallography at 3.4 Angstroms and is shown both at the bottom left (space filled depiction) and in the centre of the image within a composite model (white - in protein cartoon structure depiction) [1]. In silico modeling with Phyre was performed to obtain a structural model of the GP mucin-like domain (space filled top right monomer) [3], and also incorporated into the central composite image (yellow top). An in silico model for the GP membrane proximal stalk domain was additionally composed and is represented in trimeric configuration (space filled - bottom right) and in the centre composite (yellow strands - at the bottom) [3]. These in silico modelled structures are mapped into the composite shown in the centre with 3 separate mucin-like domains represented in yellow at the top of the trimer model, and at the base of that structure a homotrimeric stem (also in yellow) [4,5]. Together these components: the mucin-like (in silico modeled), core binding and fusion (x-ray crystal defined) and GP-membrane stalk (in situ modeled) regions cover the whole GP (i.e. $\mathrm{GP} 1+\mathrm{GP} 2$ ) monomer sequence and represent the pre-fusion conformation. These have been mapped in $3 \mathrm{D}$ space as trimers, and dispayed within the GP structure framework provided by the cryoelectron tomograph of the global GP trimer configuration. The tomograph is shown in surface view in the top left of the figure and in the central composite image as a blue mesh background. Note: the structures of the central composite are enlarged relative to their peripherally displayed individual elements.

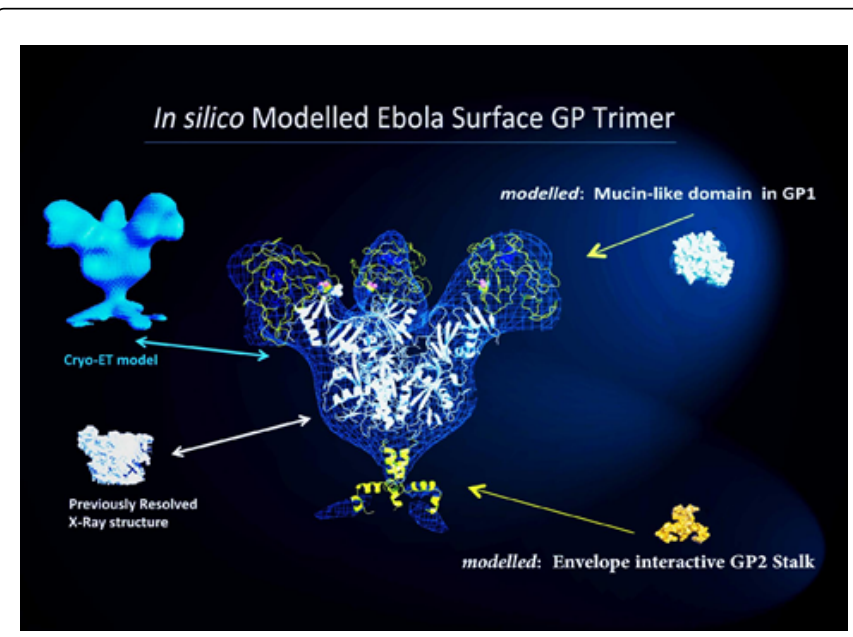

Figure 1: Compilation of a full trimeric prefusion model of the Ebola virus (EBOV) surface envelope glycoprotein GP.

\section{References}

1. Lee JE, Fusco ML, Hessell AJ, Oswald WB, Burton DR, et al. (2008) Structure of the Ebola virus glycoprotein bound to an antibody from a human survivor. Nature 454: 177-182.

2. Tran EE, Simmons JA, Bartesaghi A, Shoemaker CJ, Nelson E, et al. (2014) Spatial localization of the Ebola virus glycoprotein mucin-like domain determined by cryo-electron tomography. J Virol 88: 10958-10962.

3. Kelley LA, Sternberg MJ (2009) Protein structure prediction on the Web: a case study using the Phyre server. Nat Protoc 4: 363-371.

4. DeLano WL (2002) The PyMOL Molecular Graphics System, DeLano Scientific, Palo Alto, Ca, USA.

5. Guex N, Peitsch MC (1997) SWISS-MODEL and the Swiss-PdbViewer: an environment for comparative protein modeling. Electrophoresis 18: 2714 2723. 